\title{
Schwannoma of the tongue
}

\author{
Keiichi Ohta DDS, Hitoshi Yoshimura DDS PhD
}

Cite as: CMAJ 2021 January 18;193:E98. doi: 10.1503/cmaj.201039

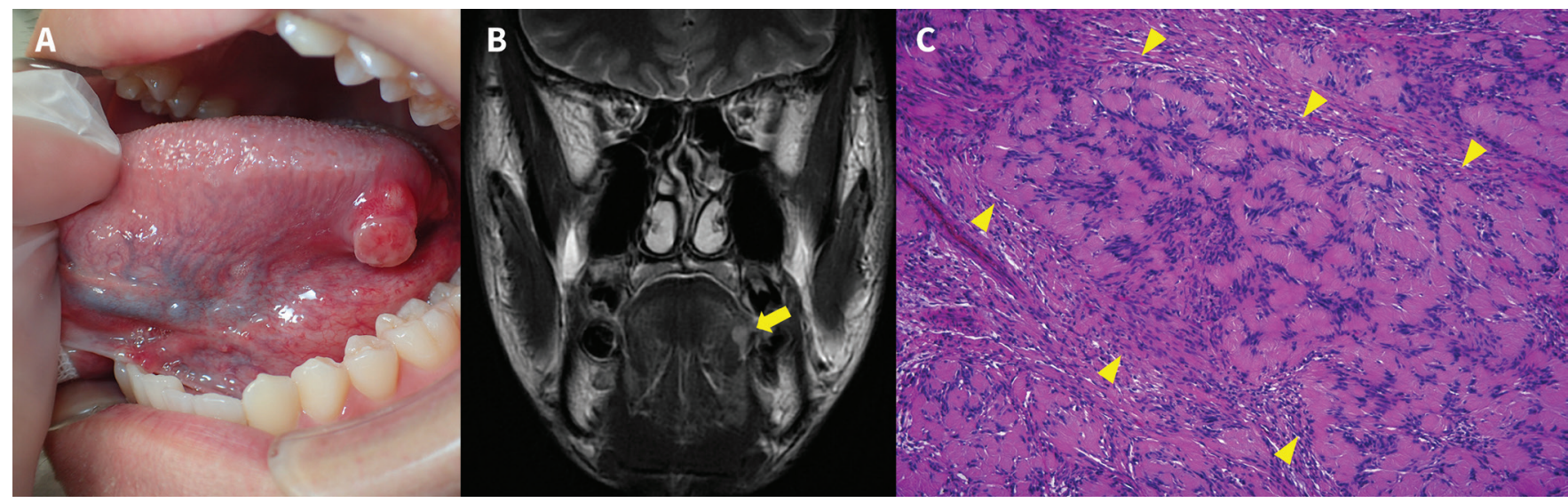

Figure 1: (A) Photograph of a well-circumscribed, elastic $14 \times 9 \mathrm{~mm}$ mass on the left lateral border of the tongue in a 17-year-old male with schwannoma. (B) Magnetic resonance imaging scan showing a well-defined lesion that was hyperintense on $T_{2}$-weighted imaging (arrow). (C) Histopathological examination with hematoxylin and eosin staining showing hypercellular spindle cell regions (arrows) in a palisading arrangement (Antoni A) (magnification $\times 100)$.

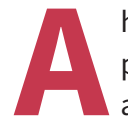

healthy 17 -year-old male presented with a 2-week history of pain in his left lateral tongue. Intraoral examination showed a well-circumscribed, elastic $14 \times 9 \mathrm{~mm}$ nodule on the left lateral tongue with tenderness to palpation (Figure 1A). Extraoral examination did not show any cervical lymphadenopathy. Magnetic resonance imaging (MRI) showed a well-defined lesion in the left lateral tongue that was isointense relative to the muscle on $T_{1}$-weighted imaging and hyperintense on $T_{2}$-weighted imaging (Figure 1B). Histopathological examination of an incisional biopsy showed hypercellular spindle cell regions in a palisading arrangement (Figure 1C). Immunochemistry results were positive for S100 and Sox 10 markers. The mass was completely excised. No evidence of recurrence was found 10 months after surgery.

A schwannoma is a benign tumour derived from Schwann cells of the nerve sheath. ${ }^{1}$ Between $25 \%$ and $45 \%$ of schwannoma cases occur in the head and neck. ${ }^{1}$ Schwannomas rarely occur in the oral cavity, but when they do the tongue is most frequently affected. ${ }^{1}$ Tongue schwannomas are usually seen in patients 20-40 years of age, with no predominance by sex. ${ }^{1}$ The lesions are slow growing and are usually asymptomatic submucosal nodules, although larger tumours in the posterior tongue may cause pain, dysphagia and dysphonia. ${ }^{1}$ Identifying the nerve origin of oral schwannomas is difficult because most of the lesions originate from smaller nerves. ${ }^{2}$ Computed tomography shows well-circumscribed, dense, homogeneous masses, and MRI is used for detailed examination. ${ }^{1}$ Schwannomas have 2 different histological features. Antoni A areas are characterized by hypercellular spindle cells in a palisading arrangement; Antoni B areas are hypocellular, disorganized cell regions. ${ }^{1-3}$ S100 and Sox10 are useful immunohistochemical markers for diagnosing peripheral nerve sheath tumours. ${ }^{4}$ Both S100 and Sox10 are used to identify neural crest differentiation, but Sox10 is a more specific marker than S100. Complete excision of schwannomas is the standard treatment. Recurrence and malignant transformation are very rare. ${ }^{1}$ All tongue lesions, even in young people, should be biopsied or excised because malignancies are possible, though uncommon.

\section{References}

1. Kavčič J, Božič M. Schwannoma of the tongue. BMJ Case Rep 2016;2016 bcr2016215799.

2. Shashikumar T, Tejaswini JS, Bellad S, et al. Ancient schwannoma: a rare intramural intra-lingual lesion. Indian J Otolaryngol Head Neck Surg 2019;71:816-9.

3. Thompson LDR, Koh SS, Lau SK. Tongue schwannoma: a clinicopathologic study of 19 cases. Head Neck Pathol 2020;14:571-6.

4. Karamchandani JR, Nielsen TO, van de Rijn M, et al. Sox10 and S100 in the diagnosis of soft-tissue neoplasms. Appl Immunohistochem Mol Morphol 2012;20:445-50.

\section{Competing interests: None declared.}

This article has been peer reviewed.

The authors have obtained patient consent.

Affiliation: Department of Dentistry and Oral Surgery, Unit of Sensory and Locomotor Medicine, Division of Medicine, Faculty of Medical Sciences, University of Fukui, Fukui, Japan

Content licence: This is an Open Access article distributed in accordance with the terms of the Creative Commons Attribution (CC BY-NC-ND 4.0) licence, which permits use, distribution and reproduction in any medium, provided that the original publication is properly cited, the use is noncommercial (i.e., research or educational use), and no modifications or adaptations are made. See: https://creativecommons.org/licenses/by-nc-nd/4.0/

Correspondence to: Keiichi Ohta, kohta@g.u-fukui.ac.jp 